Check for updates

Cite this: New J. Chem., 2022, 46,39

Received 3rd November 2021 Accepted 29th November 2021

DOI: 10.1039/d1nj05230f

rsc.li/njc

\section{9-Nitrobenzo[b]quinolizinium as a fluorogenic probe for the detection of nitroreductase in vitro and in Escherichia coli $\dagger$}

\author{
Peter Jonas Wickhorst, Heiko Ihmels, (D) * Melanie Marianne Lammert-Baumgartner, \\ Mareike Müller (D) and Holger Schönherr (D)
}

The non-fluorescent 9-nitrobenzo[b]quinolizinium is readily reduced by nitroreductase to a fluorescent reaction product. The resulting light-up effect enables the selective detection of nitroreductase activity in vitro and in Escherichia coli bacterial cultures.

Hypoxia is a condition in cells with insufficient oxygen supply, which is related to several diseases such as inflammations, ${ }^{1}$ strokes $^{2}$ or infections with the COVID-19 virus. ${ }^{3}$ Furthermore, hypoxia is an indicator of tumors, because it is observed in cancerous tissue that is disconnected from blood supply. ${ }^{4,5}$ Therefore, the detection and determination of the hypoxia status of cells is an important task in analytical biology and medicine. ${ }^{5}$ For this purpose, fluorescent probes based on organic dyes have been developed that are able to detect hypoxia-related phenomena, such as a low $\mathrm{pH}$, low oxygen levels or activity of reducing enzymes, such as azoreductase or nitroreductase, by a strong increase of their emission intensity or a distinct shift of their emission maximum in the presence of the target analyte..$^{5}$ Specifically, nitroreductase is a useful biomarker for the fluorimetric detection of hypoxic cells and bacteria with a high nitroreductase activity, e.g. Escherichia coli (E. coli) and Mycobacterium tuberculosis, ${ }^{6,7}$ as this enzyme reduces non-fluorescent substrates, such as nitroarenes, to fluorescent products in the presence of $\mathrm{NAD}(\mathrm{P}) \mathrm{H}$ as cofactor. ${ }^{4,5,8}$ However, several reaction products may be formed in this reaction along with the desired hydroxylamino- and amino-substituted fluorophores, for example in secondary reactions such as dimerization of intermediates or reduction of alkenes. ${ }^{8}$ Therefore, there is still a high demand for novel fluorogenic probes that are able to detect nitroreductase based on a clean and predictable reaction. As a result,

Department of Chemistry - Biology, University of Siegen, Center of Micro- and Nanochemistry and (Bio-)Technology (C $)$ ), Adolf-Reichwein-Str. 2, Siegen 57068, Germany.E-mail: ihmels@chemie.uni-siegen.de

$\dagger$ Electronic supplementary information (ESI) available: Experimental procedures, additional spectroscopic data, NMR spectra of $\mathbf{1 b}$ and $\mathbf{1 d}$, bacterial viability test. See DOI: 10.1039/d1nj05230f fluorescent and luminescent light-up probes that specifically target nitroreductase in living organisms have been developed based on, e.g., lanthanoid complexes, ${ }^{9}$ BODIPY, ${ }^{10}$ coumarin, ${ }^{11}$ naphthalimide, ${ }^{12}$ xanthene, ${ }^{13}$ benzothiazole, ${ }^{14,15}$ and aminosilapyronine. ${ }^{16}$ Another useful fluorophore that may be employed for this purpose is the benzo[b]quinolizinium ion (1a), which has been shown to be a versatile building block for the development of fluorescent probes for bioanalytes due to its high fluorescence quantum yield $\left(\Phi_{\mathrm{fl}}=0.52\right.$ in $\left.\mathrm{H}_{2} \mathrm{O}\right)$ and good water solubility, but it has not been utilized for enzyme detection, so far. ${ }^{17}$ Therefore, we explored the potential of quinolizinium derivatives to act as fluorescent probes for the detection of nitroreductase. To this end, we selected the 9-nitrobenzo[b]quinolizinium (1b, Fig. 1) as starting point, because the anticipated reduction product 9-aminobenzo[ $b]$ quinolizinium (1c) exhibits the highest fluorescence quantum yield $\left(\Phi_{\mathrm{fl}}=0.41\right.$ in $\left.\mathrm{H}_{2} \mathrm{O}\right)$ among the known aminobenzo $[b]$ quinolizinium derivatives. ${ }^{18}$ For comparison, the nitrostyrylsubstituted quinolizinium 2 and the nitrophenyl-substituted benzo[ $b]$ quinolizinium 1d were selected also as substrates to investigate whether structure variations have an influence on the reactivity towards nitroreductase. Herein, we demonstrate that, indeed, the 9-nitrobenzo[b]quinolizinium (1b) may be used as novel fluorogenic probe for the detection of nitroreductase in vitro and in E. coli bacteria and that, strikingly, two different emitting species are formed on reduction of $\mathbf{1 b}$ depending on the reaction conditions.

In first experiments, the absorption and emission properties of probes $\mathbf{1 b}, \mathbf{1 d}$ and $\mathbf{2}$ were investigated in aqueous buffer solution. These derivatives exhibit long-wavelength absorption

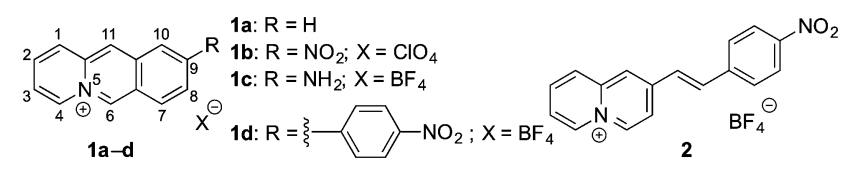

Fig. 1 Structures of quinolizinium derivatives 1 and $\mathbf{2}$. 

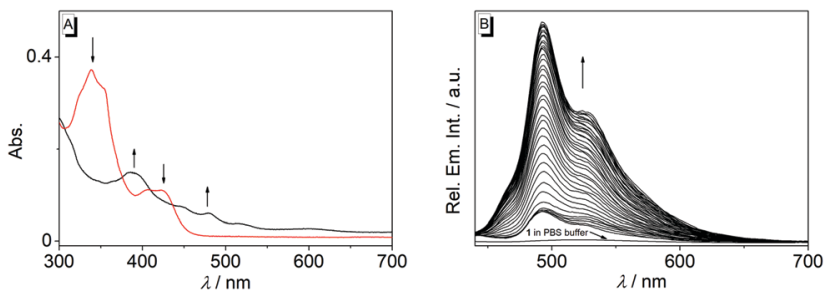

Fig. 2 (A) Absorption before (red) and after (black) incubation of probe $\mathbf{1 b}$ $(c=10 \mu \mathrm{M})$ with nitroreductase $\left(5 \mu \mathrm{gL}^{-1}\right)$ and NADH $(50 \mu \mathrm{M})$ in PBS buffer $\left(\mathrm{pH}=7, T=37^{\circ} \mathrm{C}\right.$ ) for $40 \mathrm{~min}$. (B) Change of the emission after addition of nitroreductase $\left(5 \mu \mathrm{g} \mathrm{mL}^{-1}\right)$ and $\mathrm{NADH}(50 \mu \mathrm{M})$ to probe $\mathbf{1 b}(c=$ $10 \mu \mathrm{M})$ in PBS buffer $\left(\mathrm{pH}=7, T=37^{\circ} \mathrm{C}\right) ; \lambda_{\mathrm{ex}}=415 \mathrm{~nm}$. The arrows indicate the changes of absorption and emission with increasing reaction time.

maxima at $422 \mathrm{~nm}(\mathbf{1 b}), 371 \mathrm{~nm}$ (1d) and $413 \mathrm{~nm}$ (2) (Fig. 2 and Fig. S2, ESI $\dagger$ ) and are essentially non-fluorescent in aqueous buffer solution. The low fluorescence intensity of these quinolizinium derivatives, especially as compared with the high emission quantum yield of the parent compound $\mathbf{1 a}$, is likely caused by the nitro substituent, because nitroarenes are known to undergo fast relaxation by intersystem crossing (ISC) in the excited state leading to fluorescence quenching. ${ }^{19}$ Notably, upon addition of nitroreductase and NADH all derivatives developed red-shifted absorption bands with long-wavelength absorption maxima at $480 \mathrm{~nm}$ (1b), $385 \mathrm{~nm}$ (1d), and $415 \mathrm{~nm}$ (2) (Fig. 2 and Fig. S2, ESI $\dagger$ ), indicating their reductive conversion under these reaction conditions. Specifically, the red shift is explained by the formation of an amino functionality and the resulting formation of a donor-acceptor chromophore. ${ }^{17}$ Furthermore, the reaction of compound $\mathbf{1 b}$ with nitroreductase led to the transformation of $\mathbf{1} \mathbf{b}$ into a fluorescent product with a fluorescence light-up effect $\left(\Phi_{\mathrm{fl}}=0.05\right)$, that reached its maximum intensity approx. $20 \mathrm{~min}$ after addition of the enzyme under the employed conditions (Fig. 2 and 3). In contrast, no such light-up effect was observed for derivatives 1d and 2 under the same reaction conditions, presumably
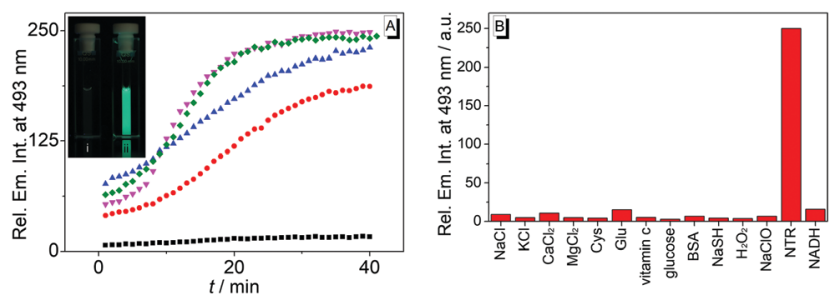

Fig. 3 (A) Change of the emission intensity during the reaction of $\mathbf{1} \mathbf{b}$ with nitroreductase at different concentrations (black: $0 \mu \mathrm{g} \mathrm{mL}^{-1}$, red: $1.25 \mu \mathrm{g} \mathrm{mL}^{-1}$, blue: $1.75 \mu \mathrm{g} \mathrm{mL}^{-1}$, green: $2.5 \mu \mathrm{g} \mathrm{mL}^{-1}$, magenta: $\left.5 \mu \mathrm{g} \mathrm{mL}^{-1}\right)$ in the presence of $\mathrm{NADH}(50 \mu \mathrm{M})$ in PBS buffer $\left(\mathrm{pH}=7, T=37^{\circ} \mathrm{C}\right) ; \lambda_{\mathrm{ex}}=415 \mathrm{~nm}$. Inset (A) Picture of the emission color before (i) and after (ii) incubation of $\mathbf{1 b}$ with nitroreductase $\left(5 \mu \mathrm{g} \mathrm{mL}^{-1}\right)$ and NADH $(50 \mu \mathrm{M})$ in PBS buffer $\left(\mathrm{pH}=7, T=37^{\circ} \mathrm{C}\right)$ for $40 \mathrm{~min}$; $\lambda_{\text {ex }}=366 \mathrm{~nm}$. (B) Relative emission intensity of solutions of $\mathrm{NaCl}(5 \mathrm{mM})$, $\mathrm{KCl}(5 \mathrm{mM}), \mathrm{CaCl}_{2}(2.5 \mathrm{mM}), \mathrm{MgCl}_{2}(2.5 \mathrm{mM})$, cystein (Cys, $\left.1 \mathrm{mM}\right)$, glutamic acid (Glu, $1 \mathrm{mM})$, vitamin $\mathrm{C}(1 \mathrm{mM})$, glucose $(1 \mathrm{mM}), \mathrm{BSA}(10 \mu \mathrm{M}), \mathrm{NaSH}$ $(10 \mu \mathrm{M}), \mathrm{H}_{2} \mathrm{O}_{2}(10 \mu \mathrm{M}), \mathrm{NaClO}(10 \mu \mathrm{M})$, nitroreductase (NTR, $5 \mathrm{mg} \mathrm{mL}^{-1}$ ) and $\mathrm{NADH}(50 \mu \mathrm{M})$ after treatment with $\mathbf{1 b}$ for 40 min in PBS buffer $(\mathrm{pH}=7$, $\left.T=37^{\circ} \mathrm{C}\right) ; \lambda_{\mathrm{ex}}=415 \mathrm{~nm}$. because the styryl and biaryl functionalities still cause emission quenching in the resulting products. Therefore, only derivative 1b was selected for further investigations. In order to determine the optimal reaction conditions, fluorescence spectra were recorded at different temperature and $\mathrm{pH}$ under otherwise identical conditions (Fig. S3, ESI $\dagger$ ). Thus, a continuous increase of the fluorescence intensity was observed with increasing $\mathrm{pH}$ and temperature up to $\mathrm{pH} 7$ and $37^{\circ} \mathrm{C}$, whereas at larger values the fluorescence intensity started to decrease. The effect of the temperature on the reaction of $\mathbf{1 b}$ with nitroreductase is in good agreement with the reported activities of the enzyme towards nitroarene derivatives ${ }^{9-11,15}$ but the optimal $\mathrm{pH}$ value lies usually slightly higher at $\mathrm{pH} 7.4 .^{9-11,15}$ The lower fluorescence intensity at higher $\mathrm{pH}$ values is presumably caused by a slow degradation of the substrate by nucleophilic addition of the hydroxide ion to the benzo[ $b]$ quinolizinium at $\mathrm{C} 6$ position and subsequent ring opening reaction, as usually observed for this class of compounds. ${ }^{20}$ Furthermore, excitation spectra indicated that the new long-wavelength absorption maxima at $447 \mathrm{~nm}$ and $480 \mathrm{~nm}$ correspond to the newly formed emitting species (Fig. 2 and Fig. S4A, ESI $\dagger$ ).

The reaction of substrate $\mathbf{1 b}$ with nitroreductase was followed at different concentrations of both components. Thus, the fluorescence intensity increased strongly with increasing concentration of compound $\mathbf{1 b}$ (Fig. 3A and Fig. S7, ESI $\dagger$ ). Furthermore, the conversion of substrate $\mathbf{1 b}$ to the reaction product was accelerated when the nitroreductase concentration was increased from $1.25 \mu \mathrm{g} \mathrm{mL}^{-1}$ to $2.5 \mu \mathrm{g} \mathrm{mL}{ }^{-1}$; however, no further increase of the reaction rate was observed at higher concentrations, i.e. $5.0 \mu \mathrm{g} \mathrm{mL}{ }^{-1}$, of the enzyme (Fig. 3A). Only at very low nitroreductase concentrations $\left(c<0.2 \mu \mathrm{g} \mathrm{mL}{ }^{-1}\right)$, an essentially linear relationship between signal intensity and nitroreductase concentration was observed, that was further utilized to determine a detection limit for the enzyme of $6 \mathrm{ng} \mathrm{mL}$ $\left(r^{2}=0.996\right.$; Fig. S4B, ESI $\left.\dagger\right),{ }^{21}$ which lies within the range of most reported nitroreductase probes $\left(0.79-48 \mathrm{ng} \mathrm{mL}{ }^{-1}\right) .{ }^{5,9-11}$

To exclude chemical conditions that can cause false positive signals, the fluorimetric response of probe $\mathbf{1} \mathbf{b}$ was examined towards components that may be encountered at physiological conditions, namely $\mathrm{NaCl}, \mathrm{KCl}, \mathrm{CaCl}_{2}, \mathrm{MgCl}_{2}$, L-cystein, L-glutamic acid, ascorbic acid, glucose, BSA, NaSH, $\mathrm{H}_{2} \mathrm{O}_{2}, \mathrm{NaClO}$ and $\mathrm{NADH}$. Notably, other than with nitroreductase, no significant changes of the emission intensity of solutions of substrate $\mathbf{1 b}$ were observed in the presence of these tested substances (Fig. 3B), which points to an undisturbed fluorescence lightup effect induced by the enzyme.

Strikingly, the absorption and emission spectra obtained after reaction of substrate $\mathbf{1 b}$ with nitroreductase/NADH did not resemble the ones of the expected product 1c. Instead, the main product exhibited a blue-shifted emission band and a redshifted absorption as compared with the spectra of 1c. ${ }^{18}$ But extraction of the aqueous reaction mixture with organic solvent and exposure of the extract to aerobic conditions for $24 \mathrm{~h}$ revealed the subsequent formation of the aminobenzoquinolizinium 1c under these conditions, as unequivocally shown by the emission band of this compound and comparison with the 
one of an authentic sample (Fig. S6A, ESI $\dagger$ ). These observations indicate that not only the nitro group, but also the benzoquinolizinium unit is reduced by nitroreductase. Indeed, it is well known that benzo[ $b]$ quinolizinium derivatives can be reduced with hydride- or hydrogen-donating reagents, such as $\mathrm{LiAlH}_{4}$, $\mathrm{NaBH}_{4}, \mathrm{H}_{2} / \mathrm{PtO}_{2}$ or $\mathrm{H}_{2} / \mathrm{Pd}$ to the dihydro- and tetrahydroquinolizinium derivatives; ${ }^{22-24}$ however, these products have been reported as colorless compounds. Yet, the deprotonation of 6,11-dihydrobenzoquinolizinium has been shown to give indirectly the reduction product $6 H$-benzo $[b]$ quinolizine as red to purple-red compound. ${ }^{23}$ Unfortunately, spectroscopic data are not available from resembling chromophores/fluorophores in the literature. But at least preliminary TD-DFT calculations revealed absorption bands, without fine structure, for compound 4 that lie in the same range as the ones observed for the primary reduction product of $\mathbf{1 b}$ (Fig. S6B, ESI $\dagger$ ). Based on the abovementioned observations, we propose that the nitro-substituted substrate $\mathbf{1 b}$ is reduced to the 9-amino-6H-benzo[b]quinolizine (4) by nitroreductase and NADH (Scheme 1).

The initially obtained organic-phase extract from the reaction mixture still showed the emission band of the primary product 4 directly after extraction and no traces of 1c. In another control experiment, it was also shown that the absorption and emission properties of the primary product did not change when it was stored in solutions that still contained nitroreductase and NADH for $24 \mathrm{~h}$. Additionally, the aminosubstituted derivative 1c was not reduced by nitroreductase/ $\mathrm{NADH}$, which indicates that $\mathbf{1 c}$ is not sensitive towards reduction under these conditions and that it is not formed as intermediate in the reaction of $\mathbf{1 b}$ with nitroreductase. In contrast, treatment of the nitro- or amino-substituted derivatives $\mathbf{1 b}$ and 1c with chemical reducing agents $\mathrm{NaBH}_{4}$ or $\mathrm{H}_{2} / \mathrm{Pd}, \mathrm{C}$ and photometric and fluorimetric monitoring of the reaction indicated the reduction to hexahydro- and tetrahydrobenzo $[b]$ quinolizine derivatives as already reported for the parent benzo $[b]$ quinolizinium. ${ }^{22}$ Only in the case of the reduction of $\mathbf{1 b}$ with $\mathrm{NaBH}_{4}$ a similar emission as the one observed on treatment with nitroreductase was temporarily detected in the course of the reaction (Fig. S6C, ESI $\dagger$ ), but it was rather weak and slightly red-shifted, presumably due to the different employed solvent systems.

Altogether, the experimental observations point to a specific transformation of the nitrobenzoquinolizinium $\mathbf{1 b}$ to 9-amino-

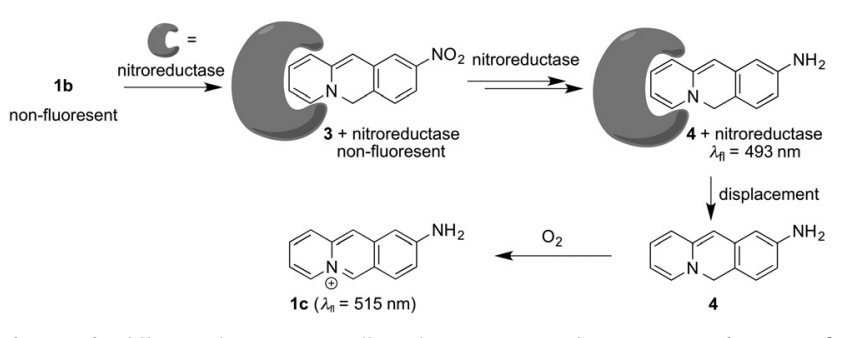

Scheme 1 Nitroreductase-mediated reaction of nitrobenzo[b]quinolizinium (1) to the proposed product 4 and subsequent oxidation to 9-aminobenzo[b]quinolizinium (1c) upon release of $\mathbf{4}$ from the binding site.
$6 H$-benzo $[b]$ quinolizine (4) by nitroreductase, because it is not formed and fairly unstable under different conditions. Therefore, it may be assumed that the primary product $\mathbf{4}$ still binds to the enzyme and is protected within the binding site against further reduction within the reaction mixture (Scheme 1). This assumption is supported by CD-spectroscopic monitoring of the reaction, because the $\mathrm{CD}$ spectrum of the enzyme in the reaction mixture changed slightly during the reaction (Fig. S5A, $\mathrm{ESI} \dagger)$, which may be caused by the association with the reaction product. ${ }^{25}$ Furthermore, the addition of acetamide as competing nitroreductase-binding ligand ${ }^{26}$ to the reaction mixture led to a slow decrease of the emission maximum at $493 \mathrm{~nm}$ of intermediate 4 in favor of the red-shifted band of the amine 1c at $510 \mathrm{~nm}$ (Fig. S5B, ESI $\dagger$ ). This change of the emission spectrum indicates the formation of compound $1 \mathrm{c}$ by displacement of 4 from the enzyme and subsequent oxidation. Overall, these observations lead to a plausible mechanism, that starts with the initial reduction of the substrate $\mathbf{1 b}$ to the 9 -amino- $6 \mathrm{H}^{-}$ benzo[ $b]$ quinolizine within the active site of the enzyme without formation of the aminobenzoquinolizinium 1c (Scheme 1). Presumably, the reduction of the heteroaromatic core takes place prior to or during the reduction of the nitro group already. Only upon release from the binding site the reactive intermediate 4 is oxidized to the final product 1c. To the best of our knowledge, such a sequence of overreduction and reoxidation that is governed by association and dissociation of the nitroarene substrate has not been reported for nitroreductase reductions.

Lastly, the potential of probe $\mathbf{1 b}$ to detect nitroreductase activity in living cells was investigated by fluorimetric analysis of $E$. coli bacteria, which are known to exhibit a high nitroreductase activity. ${ }^{7}$ The $E$. coli cultures were treated with solutions of probe $\mathbf{1 b}$ and exhibited a strong green emission after incubation for $4 \mathrm{~h}$ (Fig. 4 and Fig. S9, ESI $\dagger$ ) and did not show a bactericidal effect, even after $24 \mathrm{~h}$, as shown by a high viability of $E$. coli suspensions (Fig. S10, ESI $\dagger$ ), while previous reports have indicated a moderate growth inhibition on eukaryotic cells. $^{27}$ Fluorimetric analysis showed that compound 1c was formed as the main emitting species in E. coli, as clearly indicated by a complete match of the emission and excitation
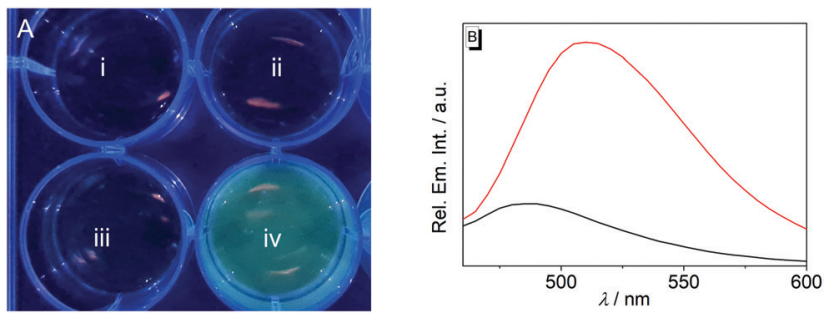

Fig. 4 (A) Photograph (acquired under illumination with $\lambda=365 \mathrm{~nm}$ ) of the emission color of Tris- $\mathrm{HCl}$ buffer (i), E. coli culture in Tris- $\mathrm{HCl}$ buffer (ii), $20 \mu \mathrm{M}$ probe $\mathbf{1 b}$ in Tris- $\mathrm{HCl}$ buffer (iii) and E. coli culture in Tris-HCL buffer after incubation with $20 \mu \mathrm{M}$ probe $\mathbf{1 b}$ (iv) for $4 \mathrm{~h}$. (B) Relative emission intensity of $E$. coli culture with an optical density of $\mathrm{OD}_{600}=0.2$ in the absence of probe $\mathbf{1 b}$ (black) and after incubation with $20 \mu \mathrm{M}$ probe $\mathbf{1 b}$ for $4 \mathrm{~h}$ (red) in Tris- $\mathrm{HCl}$ buffer; $\lambda_{\mathrm{ex}}=389 \mathrm{~nm}$. 
spectra with the ones of an authentic sample (Fig. S9C, ESI $\dagger$ ). Based on the observation in vitro, the fluorimetric response results from the initial formation of intermediate $\mathbf{4}$, which is subsequently displaced from the enzyme by competing ligands in the cells, such as acetate. ${ }^{26}$ Finally, the intermediate 4 is transformed into 1c within the bacteria, as already observed in vitro upon displacement of the nitroreductase bound compound 4 by acetamide (Fig. S5B, ESI $\dagger$ ). Since the conversion of 4 into compound $\mathbf{1 c}$ is irreversible under these conditions, even small amounts of oxygen or other oxidants like NAD ${ }^{+}$or $\mathrm{NADP}^{+}$, which are also present in $E$. coli or hypoxic cells in low concentration $^{4}$ are apparently sufficient to convert intermediate 4 into derivative 1c.

\section{Conclusions}

In summary, it was demonstrated that the nitrobenzoquinolizinium 1b has the potential to act as a probe for the fluorimetric detection of nitroreductase with a comparatively good sensing performance. ${ }^{5,9-11}$ The fluorogenic reaction in the enzyme binding site proceeds on formation of an "overreduced" intermediate 4 that is eventually transformed to the fluorescent 9-aminobenzo[b]quinolizinium (1c) upon release from the binding site. These results shall constitute the starting point for the development of a novel class of water-soluble, nitroreductase-targeting fluorescent probes based on the benzo $[b]$ quinolizinium fluorophore, which can be utilized for the fluorimetric detection of the hypoxia status of cells. Specifically, the formation of two different emitting species at different stages of the incubation, i.e. $\mathbf{4}$ and 1c, constitutes a special and so far unparalleled feature of this system that may be used to monitor nitroreductase activity at different emission wavelengths.

\section{Author contributions}

Experiments and writing (P. J. Wickhorst); experiments (M. M. Lammert-Baumgartner); supervision and writing (M. Müller, H. Schönherr, H. Ihmels).

\section{Conflicts of interest}

There are no conflicts to declare.

\section{Acknowledgements}

Generous support by the Deutsche Forschungsgemeinschaft and the University of Siegen is gratefully acknowledged. We thank Bernd Meyer, Marcus Raabe and Christoph Dohmen for technical assistance.

\section{Notes and references}

1 T. McGarry, M. Biniecka, D. J. Veale and U. Fearon, Free Radical Biol. Med., 2018, 125, 15.
2 P. Ferdinand and C. Roffe, Exp. Transl. Stroke Med., 2016, 8, 1 .

3 A. Solhpour, A. Jafari, M. A. Pourhoseingholi and F. Soltani, Trends Anaesth. Crit. Care, 2020, 34, 63.

4 A. Sharma, J. F. Arambula, S. Koo, R. Kumar, H. Singh, J. L. Sessler and J. S. Kim, Chem. Soc. Rev., 2019, 48, 771.

5 J.-N. Liu, W. Bu and J. Shi, Chem. Rev., 2017, 117, 6160.

6 S. E. Cellitti, J. Shaffer, D. H. Jones, T. Mukherjee, M. Gurumurthy, B. Bursulaya, H. I. Boshoff, I. Choi, A. Nayyar, Y. S. Lee, J. Cherian, P. Niyomrattanakit, T. Dick, U. H. Manjunatha, C. E. Barry, G. Spraggon and B. H. Geierstanger, Structure, 2012, 20, 101.

7 M. D. Roldán, E. Pérez-Reinado, F. Castillo and C. MorenoVivián, FEMS Microbiol. Rev., 2008, 32, 474.

8 K. Durchschein, M. Hall and K. Faber, Green Chem., 2013, 15, 1764.

9 B. Brennecke, Q. Wang, Q. Zhang, H.-Y. Hu and M. Nazaré, Angew. Chem., Int. Ed., 2020, 132, 8512.

10 S. Karan, M. Y. Cho, H. Lee, H. Lee, H. S. Park, M. Sundararajan, J. L. Sessler and K. S. Hong, J. Med. Chem., 2021, 64, 2971.

11 R. Peng, J. Yuan, D. Cheng, T. Ren, F. Jin, R. Yang, L. Yuan and X. Zhang, Anal. Chem., 2019, 91, 15974.

12 (a) Z. He, Y. Chou, H. Zhou, H. Zhang, T. Cheng and G. Liu, Org. Biomol. Chem., 2018, 16, 3266; (b) X. Ao, S. A. Bright, N. C. Taylorb and R. B. P. Elmes, Org. Biomol. Chem., 2017, 15, 6104.

13 K. N. More, T.-H. Lim, J. Kang, H. Yun, S.-T. Yee and D.-J. Chang, Molecules, 2019, 24, 3206.

14 Q. Yang, S. Wang, D. Li, J. Yuan, J. Xu and S. Shao, Anal. Chim. Acta, 2020, 1103, 202.

15 L. Fan, Q. Zan, B. Lin, X. Wang, X. Gong, Z. Zhao, S. Shuang, C. Dong and M. S. Wong, Analyst, 2020, 145, 5657.

16 S. Sarkar, H. Lee, H. G. Ryu, S. Singha, Y. M. Lee, Y. J. Reo, Y. W. Jun, K. H. Kim, W. J. Kim and K. H. Ahn, ACS Sens., 2021, 6, 148.

17 (a) S. Schramm and D. Weiß, Adv. Heterocycl. Chem., 2019, 128, 103; (b) E. Zacharioudakis, T. Cañeque, R. Custodio, S. Müller, A. M. Cuadro, J. J. Vaquero and R. Rodriguez, Bioorg. Med. Chem. Lett., 2017, 27, 203; (c) Y. R. Han, S.-H. Shim, D.-S. Kim and C.-H. Jun, Org. Lett., 2017, 19, 2941; (d) G. Marcelo, S. Pinto, T. Cañeque, I. F. A. Mariz, A. M. Cuadro, J. J. Vaquero, J. M. G. Martinho and E. M. S. Maçôas, J. Phys. Chem. A, 2015, 119, 2351; (e) A. Granzhan, H. Ihmels and M. Tian, Arkivoc, 2015, 6, 494; $(f)$ R. Bortolozzi, S. von Gradowski, H. Ihmels, K. Schäfer and G. Viola, Chem. Commun., 2014, 50, 8242; (g) R. Bortolozzi, H. Ihmels, L. Thomas, M. Tian and G. Viola, Chem. - Eur. J., 2013, 19, 8736. For dibenzoquinolizinium, see e.g.: (h) W.-M. Yip, Q. Yu, A. Tantipanjaporn, W.-C. Chan, J.-R. Deng, B. C.-b. Ko and M.-K. Wong, Org. Biomol. Chem., 2021, 19, 8507; (i) V. D. Kadam, B. Feng, X. Chen, W. Liang, F. Zhou, Y. Liu, G. Gao and J. You, Org. Lett., 2018, 20, 7071.

18 K. Faulhaber, A. Granzhan, H. Ihmels, D. Otto, L. Thomas and S. Wells, Photochem. Photobiol. Sci., 2011, 10, 1535. 
19 G. J. S. Zugazagoitia, C. X. Almora-Diaz and J. Peon, J. Phys. Chem. A, 2008, 112, 358.

20 (a) G. E. Gomez Pinheiro, H. Ihmels and C. Dohmen, J. Org. Chem., 2019, 84, 3011; (b) H.-J. Deiseroth, A. Granzhan, H. Ihmels, M. Schlosser and M. Tian, Org. Lett., 2008, 10, 757; (c) A. P. Krapcho, S. A. Cadamuro and L. Macnee, Arkivoc, 2007, 9, 28.

21 Y. Chen, C. Zhu, Z. Yang, J. Chen, Y. He, Y. Jiao, W. He, L. Qiu, J. Cen and Z. Guo, Angew. Chem., Int. Ed., 2013, 52, 1688.

22 T. Miyadera and R. Tachikawa, Tetrahedron, 1969, 25, 5189.

23 L. L. Braun and C. K. Bradsher, J. Org. Chem., 1968, 33, 1296.
24 C. Bradsher and N. Yarrington, J. Org. Chem., 1960, 25, 294. 25 A. Rodger, R. Marrington, D. Roper and S. Windsor, in Protein-Ligand Interactions, ed. G. U. Nienhaus, Humana Press, New Jersey, 2005, pp. 343-364.

26 P. R. Race, A. L. Lovering, R. M. Green, A. Ossor, S. A. White, P. F. Searle, C. J. Wrighton and E. I. Hyde, J. Biol. Chem., 2005, 280, 13256.

27 For cytotoxicity of the reduction product 1c, see: A. K. Ernst, M. Liebscher, S. Mathea, A. Granzhan, J. Schmid, M. R. Popoff, H. Ihmels, H. Barth and C. Schiene-Fischer, Sci. Rep., 2016, 6, 20301. 